\title{
Development of Resource-Saving Technological Processes for Manufacturing Rings by the Compression Method
}

\author{
V. Yu. Lavrinenko ${ }^{1,}{ }^{*}$ and $A . O$. Polyakov ${ }^{1}$ \\ ${ }^{1}$ Bauman Moscow State Technical University, Moscow, 105005, Russia
}

\begin{abstract}
Based on the developed methodology for designing technological processes for producing annular parts by compression, we developed technological processes for manufacturing parts "Flange" and "Thrust ring", which make it possible to increase the material utilization factor (MUF) and reduce material consumption. A comparative analysis of MUF in the manufacture of annular parts by cutting and punching rings with cutting and punching of an oval workpiece and subsequent compression.
\end{abstract}

Efficient use of metal and increasing the material utilization factor (MUF) is an important task in the development of various metal forming processes.

The application of the compression method of an oval workpiece in the manufacture of thin-sheet annular parts [1] allows an increase in the material utilization factor up to 1,2-1,5 times in conditions of mass production in comparison with the method of cutting and punching and up to 4 times in the conditions of a single production in comparison with by turning on a lathe.

As a result of the experimental and theoretical studies of the compression process of the initial oval workpieces in the manufacture of annular parts, the range of rational use of this method was determined, which can be used to select the technology for the manufacture of annular parts. Also, a special die was developed for the production of the annual parts by the compression method, which allows obtaining high-quality annular parts. Moreover, formulas were obtained for determining the geometric parameters of the original oval workpiece and dependencies, taking into account the displacement of the neutral layer of deformations, the relative deviation from the roundness of the inner and outer diameters, the relative thinning and thickening of the final annular part.

As a result, for designing technological processes for producing annular parts by compression a method was developed, the use of which makes it possible to increase the material utilization factor [2-5].

Following this methodology, technological processes were developed for manufacturing parts "Flange" of copper grade M3 (GOST 1173-2006) and "Thrust ring" from AMg3 aluminium alloy (GOST 13726-97) (Figure 1).

${ }^{*}$ Corresponding author: ieec@bk.ru 


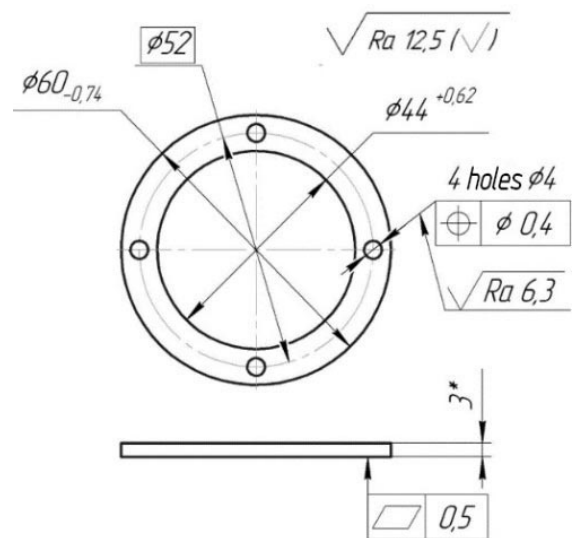

(a)

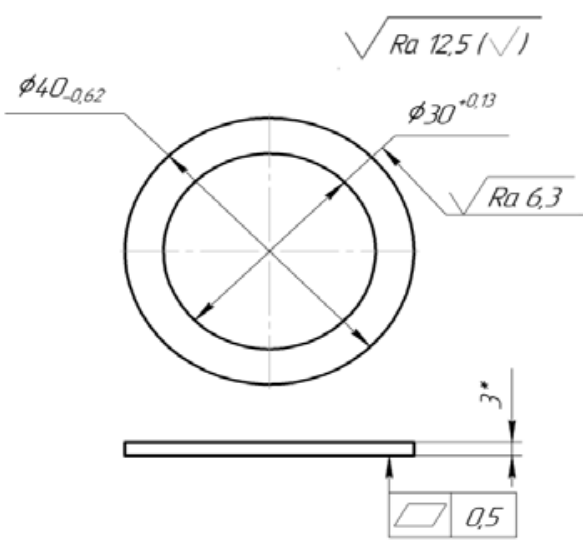

(b)

Fig. 1. Annular parts drawings: (a) "Flange"; (b) "Thrust ring".

The production program for the parts "Flange" and "Thrust ring" 162 pcs. and 360 pcs. respectively, according to the manufacturer of the parts, the dimensions of the sheet used are $1000 \times 500 \times 3$. According to the existing technology, the parts "Flange" and "Thrust ring" are obtained using cutting/punching operations during staggered cutting, while the MUF can be determined by the formula:

$$
K_{u}=\frac{f \cdot n}{E \cdot C}
$$

where $f-$ is the area of the part, $\mathrm{mm}^{2} ; C$ - is the sheet length, $\mathrm{mm} ; E-$ is the sheet width, $\mathrm{mm} ; n-$ is the number of parts.

MUF, in this case, is 0,35 and 0,32 for parts "Flange" and "Thrust ring", respectively.

Under the developed technique [4-5], the main technological parameters of the process of manufacturing annular parts by compression were determined. The minimum radius of the original oval workpiece is determined by the formula:

$$
r_{\text {min } \_}=\frac{r_{p}}{2 \cdot(\delta+1)}
$$

where $r_{p}$ - is the inner radius of the part, $\mathrm{mm} ; \delta$ - is the relative elongation of the steel.

For the part "Flange" $r_{\text {min } C}=7,45 \mathrm{~mm}$ and for the part "Thrust ring" $r_{\text {min } C}=6,5 \mathrm{~mm}$.

The inner radius of the workpiece is calculated by the formula:

$$
r_{w}=\frac{r_{p}+B \cdot(x-1)}{2}
$$

where $x$ - is the coefficient of displacement of the neutral layer of deformations; $B$ - is the width of the wall of the part of the "ring" type, $\mathrm{mm}$.

Accordingly, for the "Flange" part $r_{w}=9,86 \mathrm{~mm}$ and for the "Thrust ring" part $r_{w}=$ $6,9 \mathrm{~mm}$.

As a result, the inner radius of the oval workpiece for the "Flange" part and the "Thrust ring" part turned out to be larger than the minimum radius, which satisfies the following condition:

$$
r_{w} \geq r_{\text {min } \_} C
$$

The length of the rectilinear section we find by the formula:

$$
A=\frac{\pi \cdot\left(r_{p}+B \cdot x\right)}{2}
$$


The length of the straight section $A$ for the "Flange" part is $A=43,6 \mathrm{~mm}$, and for the part "Thrust ring" part $-A=29,5 \mathrm{~mm}$.

According to formulas (2) - (5), the main geometric dimensions of oval workpieces were determined, sketches of the original oval workpieces are shown in Figure 2.

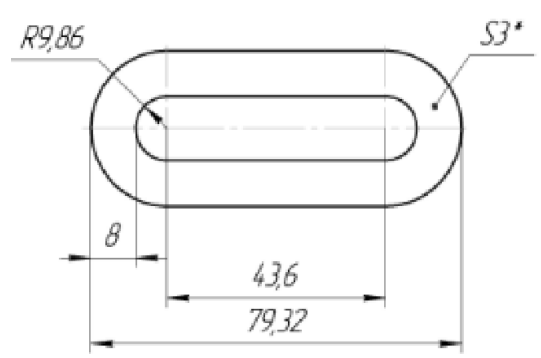

(a)

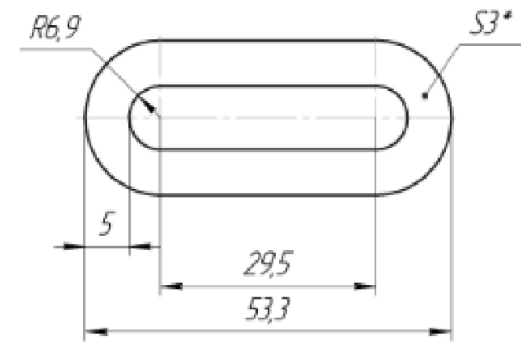

(b)

Fig. 2. Sketches of oval workpieces for the manufacture of parts: a) "Flange"; b) "Thrust ring".

Further, the values of the standard deviation from roundness were determined using the developed regression equations [3, 4]:

- for the outer diameter $\sigma_{\text {out }}$ :

$$
\sigma_{\text {out }}=0,042+0,0012 \cdot\left(\frac{B}{S}-2,663\right)-0,015 \cdot\left(\frac{A}{r_{p}}-2,417\right)+0,05 \cdot\left(\frac{r_{w}}{r_{p}}-0,42\right)
$$

where $S$ - is the thickness of the part, $\mathrm{mm}$.

In this case, the standard deviation from the roundness of the outer diameter for the "Flange" part and the "Thrust ring" part was $\sigma_{\text {out }}=0,05 \mathrm{~mm}$;

- for the inner diameter $\sigma_{i n}$ :

$$
\sigma_{\text {in }}=0,509+0,113 \cdot\left(\frac{B}{S}-2,663\right)+0,565 \cdot\left(\frac{A}{r_{p}}-2,417\right)+1,25 \cdot\left(\frac{r_{w}}{r_{p}}-0,42\right)
$$

The standard deviation from the roundness of the inner diameter for the "Flange" part is $\sigma_{\text {in }}=0.298 \mathrm{~mm}$, for the "Thrust ring" part $-\sigma_{\text {in }}=0.193 \mathrm{~mm}$.

It is necessary to pay attention that for the "Thrust ring" part the high requirements are imposed on the accuracy of the inner diameter. The standard deviation from the roundness of the inner hole exceeds the tolerance for the inner diameter in the drawing, therefore, calibration in the calibration die is required in the future.

Moreover, using the developed regression equations [3, 4], the relative thickness of the part was determined:

- for the inner side of the received part $S_{i n}$ :

$$
\frac{s_{\text {in }}}{S}=0,924-0,0042 \cdot\left(\frac{B}{S}-2,663\right)-0,05 \cdot\left(\frac{A}{r_{p}}-2,417\right)-0,175 \cdot\left(\frac{r_{w}}{r_{p}}-0,42\right)
$$

The relative thickness of the part in the dangerous section from the inside for the "Flange" part is $S_{i n} / S=0,941$, for the "Thrust ring" part $-S_{\text {in }} / S=0,944$;

- for the outer side of the received part $S_{\text {out }}$ :

$$
\frac{S_{\text {out }}}{S}=1,093-0,004 \cdot\left(\frac{B}{S}-2,663\right)-0,006 \cdot\left(\frac{A}{r_{p}}-2,417\right)-0,075 \cdot\left(\frac{r_{w}}{r_{p}}-0,42\right)
$$

The relative thickness of the part in the dangerous section from the outside for the "Flange" part is $S_{\text {out }} / S=1,093$, for the "Thrust ring" part $-S_{\text {out }} / S=1,089$. 
To select the necessary pressure equipment, the calculation of the maximum compression force of the original oval workpiece was also carried out according to the formula:

$$
P_{\max }=S \cdot D \cdot \sigma_{B} \cdot k
$$

where $D$ - is the diameter of the annular part, mm, $\sigma_{B}-$ is the ultimate strength of the workpiece material, $\mathrm{MPa} ; S-$ is the workpiece thickness, mm, $k-$ is the coefficient depending on the ratio of the width to the workpiece thickness $B / S$. The selection of the coefficient $\mathrm{k}$ is carried out by Table 1 .

Table 1. The value of the coefficient $k$ from the relative width of the annular part $B / S$.

\begin{tabular}{|c|c|}
\hline$B / S$ & $k$ \\
\hline from 1 to 2 & $0,5 \cdot \frac{B}{S}+0,25$ \\
\hline from 2 to 3 & $0,1 \cdot \frac{B}{S}+0,4$ \\
\hline from 3 to 4 & $0,02 \cdot \frac{B}{S}+0,45$ \\
\hline
\end{tabular}

The maximum compression force of the workpiece was: for the "Flange" part $P_{\max }=23400 \mathrm{~N}$, for the "Thrust ring" part $-P_{\max }=11232 \mathrm{~N}$.

Based on the results of theoretical calculations, process flow diagrams were developed for the parts "Flange" and "Thrust ring", the necessary equipment was selected (Table 2).

Table 2. Process flow diagrams of the manufacturing process of (a) "Flange" and (b) "Thrust ring" parts.

\begin{tabular}{|c|c|c|c|}
\hline \multicolumn{4}{|c|}{ (a) The"Flange" part } \\
\hline № & Operation name & Sketch & Equipment, instruments \\
\hline 1 & $\begin{array}{l}\text { Laser cutting of raw } \\
\text { oval workpieces }\end{array}$ & $R 9.86$ & $\begin{array}{l}\text { Laser cutting machine Trumpf } \\
\text { LY } 2500 \text { YAG laser } 800 w\end{array}$ \\
\hline 2 & Compression & 960 & $\begin{array}{l}\text { Press KD 2330, nominal force } 1 \\
\text { MN, compression die }\end{array}$ \\
\hline 3 & Testing & $\begin{array}{c}\sigma_{\text {out }}=0,05<0,74 \mathrm{~mm}, \\
\sigma_{\text {in }}=0,298<0,62 \mathrm{~mm}, \\
S_{\text {in }} / S=0,941, S_{\text {out }} / S=1,093 \\
\text { no ring calibration required }\end{array}$ & $\begin{array}{l}\text { Digital Micrometer MCD-25; } \\
\text { Vernier caliper Matrix } 31611\end{array}$ \\
\hline
\end{tabular}




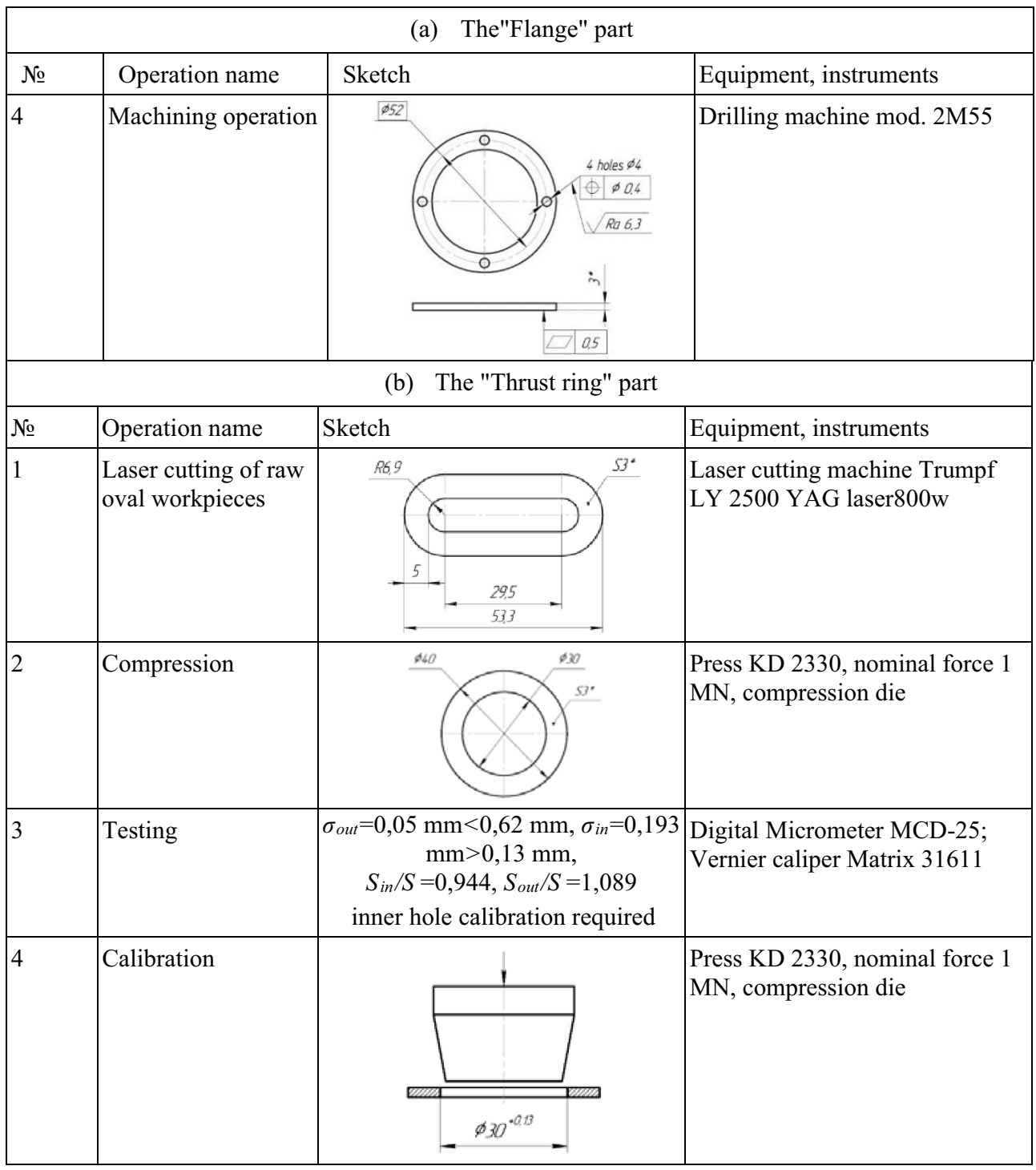

\section{Conclusion}

1. The values of MUF for new technological processes of manufacturing parts "Flange" and "Thrust ring" by compression were 0,45 and 0,42 , respectively, thus, the use of the compression method will increase the MUF by 1,28 and 1,31 times, respectively.

2. The developed methodology for designing technological processes for the manufacture of annular parts by compression makes it possible to increase the material utilization factor up to 1,5 times and reduce costs in the conditions of single and small-scale production while ensuring the required quality of the manufactured parts. Production of parts by compression method making is a more economical and resource-saving process for making some annular parts compared to cutting and punching. 


\section{References}

1. Semenov E I, Ayrapetyan A S and Demin M V 2014 New method of ring production by compression methodWorkpiece production in mechanical engineering 10 15-8.

2. Lavrinenko V, Polyakova A and Polyakov A 2018 Analysis of the applicability of die pressing method for ring-shaped parts fabrication MATEC Web of Conf.224 02074.https://doi.org/10.1051/matecconf/201822402074.

3. Lavrinenko V Yu, Polyakov A O and Mirvelyan T A 2019 Development of the stamp design for ring-shaped parts manufacturing by compression method Materials Today: Proc.19(5) 2106-8. https://doi.org/10.1016/j.matpr.2019.07.219.

4. Polyakov A O and Lavrinenko V Yu 2020 Development of a methodology for the design of technological processes for the manufacture of ring-type parts by compression Fundamental and applied problems of engineering and technology 42(342) 61-8.

5. Polyakov A O, Lavrinenko V Yu and Semenov I E 2021 Development of the design technique of technological processes for manufacturing of ring-shaped parts by compression Materials Today: https://doi.org/10.1016/j.matpr.2020.08.098.

38(4) 1343-7. 